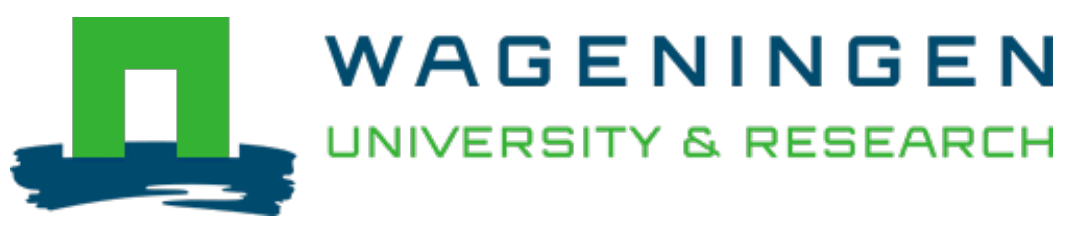

\title{
Relationship between MODIS EVI and LAI across time and space
}

Geocarto International

Alexandridis, Thomas K.; Ovakoglou, Georgios; Clevers, Jan G.P.W.

https://doi.org/10.1080/10106049.2019.1573928

This article is made publicly available in the institutional repository of Wageningen University and Research, under the terms of article $25 \mathrm{fa}$ of the Dutch Copyright Act, also known as the Amendment Taverne. This has been done with explicit consent by the author.

Article $25 \mathrm{fa}$ states that the author of a short scientific work funded either wholly or partially by Dutch public funds is entitled to make that work publicly available for no consideration following a reasonable period of time after the work was first published, provided that clear reference is made to the source of the first publication of the work.

This publication is distributed under The Association of Universities in the Netherlands (VSNU) 'Article $25 \mathrm{fa}$

implementation' project. In this project research outputs of researchers employed by Dutch Universities that comply with the legal requirements of Article $25 \mathrm{fa}$ of the Dutch Copyright Act are distributed online and free of cost or other barriers in institutional repositories. Research outputs are distributed six months after their first online publication in the original published version and with proper attribution to the source of the original publication.

You are permitted to download and use the publication for personal purposes. All rights remain with the author(s) and / or copyright owner(s) of this work. Any use of the publication or parts of it other than authorised under article $25 \mathrm{fa}$ of the Dutch Copyright act is prohibited. Wageningen University \& Research and the author(s) of this publication shall not be held responsible or liable for any damages resulting from your (re)use of this publication.

For questions regarding the public availability of this article please contact openscience.library@,wur.nl 
Geocarto International

ISSN: 1010-6049 (Print) 1752-0762 (Online) Journal homepage: https://www.tandfonline.com/loi/tgei20

\section{Relationship between MODIS EVI and LAI across time and space}

\section{Thomas K. Alexandridis, Georgios Ovakoglou \& Jan G. P. W. Clevers}

To cite this article: Thomas K. Alexandridis, Georgios Ovakoglou \& Jan G. P. W. Clevers (2019): Relationship between MODIS EVI and LAI across time and space, Geocarto International, DOI: 10.1080/10106049.2019.1573928

To link to this article: https://doi.org/10.1080/10106049.2019.1573928

Accepted author version posted online: 30 Jan 2019. Published online: 06 Mar 2019.

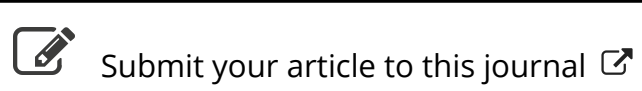

Џ Article views: 32

View Crossmark data ¿ 


\title{
Relationship between MODIS EVI and LAI across time and space
}

\author{
Thomas K. Alexandridis ${ }^{\mathrm{a}}$ (D), Georgios Ovakoglou ${ }^{\mathrm{a}}$ (D) and \\ Jan G. P. W. Clevers ${ }^{b}$ iD \\ aLaboratory of Remote Sensing, Spectroscopy and GIS, School of Agriculture, Aristotle University of \\ Thessaloniki, Thessaloniki, Greece; ${ }^{b}$ Laboratory of Geo-Information Science and Remote Sensing, \\ Wageningen University \& Research, Wageningen, The Netherlands
}

\begin{abstract}
The Leaf Area Index (LAI) is used as input in hydrological and biochemical models for the estimation of water-cycle characteristics, agricultural primary production and other processes. Vegetation Indices (VIs) are used to monitor vegetation state and health. Considering that easily computed VIs can be used for the estimation of LAl, this study applied a regression analysis between MODIS Enhanced Vegetation Index (EVI) and LAI data in five sites around the world. A linear model was found to provide a good description of the LAI-EVI relationship across all examined vegetation types and times. Medium accuracy models were improved when variability of time and vegetation type were considered, indicating that these parameters highly affect the LAI-EVI relationship. Sensitivity of EVI to LAI was higher in periods of high biomass production. Regression analysis between LAI-EVI showed a stronger relationship for the study sites characterized by dry and warm tropical climatic conditions.
\end{abstract}

\section{ARTICLE HISTORY}

Received 1 August 2018

Accepted 17 January 2019

\section{KEYWORDS}

MODIS LAl; MODIS EVI; regression analysis; vegetation type

\section{Introduction}

The Leaf Area Index (LAI) is an important parameter characterizing vegetation and is defined as the one-sided green leaf area per unit ground area in broadleaf canopies and as one half the total needle surface area per unit ground area in coniferous canopies (Myneni 2012). Knowledge of LAI is crucial in order to describe vegetation development within an ecosystem. It is widely used as a basic input parameter in hydrological and biochemical models for the estimation of the water-cycle, agricultural primary production, exchange of carbon dioxide, desertification risk, etc. Moreover, LAI can define the water loss by evapotranspiration, roughness for surface water flow and development stage of plants (Teixeira 2010; Jassas et al. 2015).

Measuring LAI in situ is a difficult and costly process (Alexandridis et al. 2013). Remote sensing can be used instead to acquire LAI data at various spatiotemporal scales. Several products are available from the Food and Agriculture Organization of the United Nations (FAO), the European Space Agency (ESA) and the National Aeronautics and 
Space Administration (NASA) for this purpose, providing LAI maps at regional or global scales, at high frequency (8-day interval), but at low spatial resolution (500-1000 m). The underlying hypothesis for estimating LAI (Knyazikhin et al. 1999) is that increased vegetation biomass, which is related to increased LAI values, causes an increase in near-infrared reflectance and red absorbance (thus a decrease in red reflectance).

Three basic methods are commonly applied in remote sensing for estimating LAI: (1) the empirical based model, relating Vegetation Indices (VIs) with in situ LAI estimations (Clevers 1989; Butson and Fernandes 2004; Nyokabi and Laneve 2004; Soudani et al. 2006), (2) the radiative transfer model, which uses physical laws to describe with accuracy the spectral variation of canopy reflectance as a function of canopy, leaf and soil background (Goel 1989; Kimes et al. 2000; Meroni et al. 2004) and (3) the hybrid model, which combines the advantages of both previous methods into an integrated LAI inverse model (Shen et al. 2014).

To facilitate monitoring vegetated areas, and to easily account for atmospheric influence, canopy structure or soil background, VIs are often being calculated using a combination of visible (mostly red) and near-infrared bands (Huete et al. 1999; Silleos et al. 2014). From the available VIs reported in literature for the estimation of LAI, the Normalized Difference Vegetation Index (NDVI) and the Enhanced Vegetation Index (EVI) are the most commonly used VIs (Wang, Adiku, et al. 2005). A major disadvantage related to the use of the NDVI is the saturation of the index at high LAI values. The EVI has improved sensitivity in high biomass regions and is more sensitive to variations in canopy structure (Chen and Sun 2010). An additional advantage is that EVI uses the reflectance in the blue band for minimizing atmospheric influences (Huete et al. 1997).

Studying the relationship between LAI and satellite derived VIs is not a newly introduced concept. Several attempts have been recorded in relevant literature, for example Myneni et al. (2002), in examining the non-linear relation between NDVI and LAI, as well as the near-linear relation between NDVI and the fraction of absorbed photosynthetically active radiation (fPAR). On the other hand, Wang, Adiku, et al. (2005) examined the relationship between LAI patterns estimated using a radiative transfer model with input of above and below canopy measurements of global radiation, with the satellite derived values of EVI and NDVI for a deciduous forest study area, finding a near-perfect linear relationship between LAI and NDVI $\left(R^{2}=0.99\right)$, as well as between LAI and EVI values $\left(R^{2}=0.92\right)$.

Relevant research usually focuses on certain types of crops or natural vegetation and the methods are applied on small study sites characterized by a single type of climatic conditions. Additionally, their focus is mainly on specific phenological stages and the seasonal relationship of VIs vs. LAI is less explored (Wang, Adiku, et al. 2005). To our knowledge, there is no relevant research up to now taking simultaneously into consideration all available types of vegetation (both natural and agricultural) present in a study site in order to analyze the relationship between the LAI and a VI. Moreover, since climatic conditions highly affect vegetation development, it would be interesting to examine whether climatically diverse study areas, which are subsequently characterized by strong inter-variability considering the vegetation species present, could return consistent results during the analysis of the LAIEVI relationship. Therefore, the aim of this work was to examine the relationship between EVI and LAI using the widely available MODerate resolution Imaging Spectrometer (MODIS) data, and identify the most important characteristics affecting this relationship during a hydrological year, across different vegetation types and for different climates. 


\section{Materials and methods}

\section{Study areas}

Catchment areas of rivers located in Greece, Portugal, the Netherlands, Mozambique and Brazil, including the cross-border areas (Figure 1), were selected as the study sites for this work.

The selected areas provided a relatively high diversity of natural vegetation types and agricultural systems. Nestos (Greece) has a Mediterranean climate and the river basin is mainly covered by forests, shrubs and grassland, while the main areas of intensive agricultural land can be found in the floodplain and consist of single crop cycle plants and tree crops.

Tamega (Portugal) has a warm temperate, Mediterranean climate. The land cover is mainly shrubs and forest, and crops are located along the river, mainly including fields with a single crop cycle.

Rijnland (the Netherlands) has a temperate oceanic climate and the catchment area is mainly covered with herbaceous rainfed crops and pastures. Considering the farming areas of Rijnland, the fields are all rainfed and the most frequent crop found in the area is pasture for grazing purposes. Several other crops with a single cropping cycle are also present, as well as greenhouses.

In Queimados (Brazil) the climate is characterized as dry-tropical and the study area is mainly covered by herbaceous rainfed crops and grasslands, while there is also a strong presence of sparse broad-leaved forests and shrubs (cerrado). The agricultural activities in Queimados might have more than one cropping cycle per year, while the main crops cultivated in the area include grains, soybeans, rice, corn, wheat and beans.

Umbeluzi (Mozambique) has a warm tropical climate and its main vegetation types are grasslands and shrubs. Due to the climate conditions present in the Umbeluzi sub-basin, it is possible that more than one cropping cycle per year might occur for some of the crops cultivated. Apart from only a few but very large sized irrigated plantations, there are also some small-scale irrigated fields. The rest of the agricultural land is rainfed and is consisting of small fields with mixed natural vegetation (grasses and bushes), and with a few fruit trees.

\section{Data}

From the freely available LAI and EVI data, the products of the Terra MODIS satellite were used. LAI was estimated using a biome dependent radiative transfer model

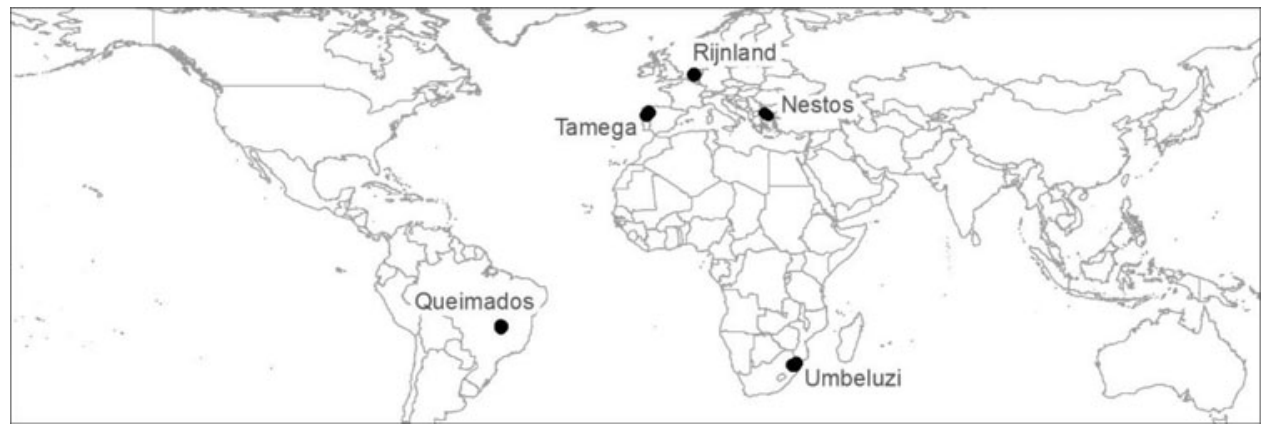

Figure 1. Geographic distribution of study sites. 
(Knyazikhin et al. 1999), using the MODIS spectral bands after classifying the globe into six different biomes (also using MODIS). A Look-Up Table (LUT) approach was used to achieve inversion of the radiative transfer model. The selected MODIS LAI product (MCD15A2) presents 8-day composites at $1000 \mathrm{~m}$ spatial resolution retrieved from daily, atmospherically corrected, bi-directional surface reflectance data. However, a 16-day timestep was chosen, because this coincides with the time-step of the MODIS EVI product (MOD13A2) at the same spatial resolution. A time-series of MODIS LAI and EVI products covering a hydrological year (October 2012-September 2013) was downloaded, resulting in 23 pairs of LAI and EVI images per study area. Each image downloaded also included the Quality Assurance layers (QA), indicating the quality of the data per pixel in the associated images (low, marginal and good quality). These layers were used in order to detect and exclude the LAI and EVI pixels characterized by low or marginal quality and subsequently use only the data indicated as of good quality, similar to Wang, Tenhunen, et al. (2005), who suggested that low and marginal data should be used with caution and only when there is a large data gap.

Additionally, land-cover data were used in order to divide the pixels of the LAI and EVI images according to the vegetation type category they fall into, derived from the GlobCover dataset (300 m spatial resolution, http://due.esrin.esa.int/page_globcover.php). The original vegetation classes from GlobCover were grouped into six biomes, somewhat similar to those used by the MODIS land-cover product, but not identical to those of MODIS: irrigated crops, rainfed crops, broadleaved forests, needle-leaved forests, shrublands and grasslands.

\section{Methods}

The pre-processing of all satellite products included the conversion of the associated images to TIFF format, the assignment of the UTM/WGS'84 coordinate system according to the related geographic zone of each study site, and clipping the data within the boundaries of the areas of interest (river basins).

For each one of the study sites, a point-sample file was created using the centre of the pixels in a single MODIS image per study area, due to the common geometry of the MODIS time-series of images used $(1000 \mathrm{~m}$ vertical and horizontal distance per point, same as MODIS pixel resolution). As a next step, the pixels that were associated with non-vegetated areas were excluded using overlay analysis with the GlobCover dataset, in order to not interfere with further analyses.

In addition, the pixels of low and marginal quality were excluded from each dataset using overlay analysis with the MODIS QA layer. The categories of low QA data include pixels covered by ice, water and clouds, as well as the pixels affected by aerosol/cirrus presence or errors in the source data (Dead Detector). For marginal quality characterized pixels the backup algorithm of MODIS LAI was used to estimate their values (https:// modis.gsfc.nasa.gov/data/atbd/atbd_mod15.pdf).

To avoid the influence of pixels of mixed vegetation, a buffer of $300 \mathrm{~m}$ at each side of the border between different vegetation types was created, derived from the GlobCover dataset, and pixels falling within the buffer were excluded. GlobCover data use a spatial resolution approximately three times finer than the MODIS pixel $(300 \mathrm{~m}$ instead of $1000 \mathrm{~m}$ ), so it was also feasible to provide better detail and accuracy in excluding the mixed-vegetation pixels, than in case of using a land-cover product of a $1000 \mathrm{~m}$ spatial resolution - same as MODIS data. The remaining pixels were the final dataset used in subsequent analyses. 
In order to identify the relationship between EVI and LAI, regression analysis between the two MODIS products was used on a per-pixel basis. Analyses were repeated to evaluate the type of regression equation, the appearance of a seasonal effect, as well as the influence of vegetation type. The nature of the LAI-EVI relation was examined by evaluating the coefficient of determination $\left(R^{2}\right)$ with its significance as probability values ( $p$ value), the Root Mean Square Error (RMSE), the number of sample pixels participating in each case of regression analysis, as well as by examining the scatter plots.

\section{Results}

A regression analysis between EVI and LAI was applied for all good quality pixels of each study area's time series of images (Table 1). Linear and polynomial equations returned the highest values of $R^{2}$ and lowest RMSE in all study areas, with only marginal differences between them.

Visualizing the polynomial and linear lines in the scatter plots, they both had a similar fit to the data (Figure 2). The reason for this similarity is the density of the pixels that appears along a line (Nestos, Rijnland), along two lines (Queimados and Tamega) and only slightly deviating from a line in the case of Umbeluzi. Thus, considering the

Table 1. Regression analyses results between EVI and LAI per study area ( $p<.001$ in all cases).

\begin{tabular}{|c|c|c|c|c|c|c|c|c|}
\hline \multirow[b]{2}{*}{ Study area } & \multicolumn{2}{|c|}{ Linear } & \multicolumn{2}{|c|}{ Squared } & \multicolumn{2}{|c|}{ Square root } & \multicolumn{2}{|c|}{ Polynomial } \\
\hline & $R^{2}$ & RMSE & $R^{2}$ & RMSE & $R^{2}$ & RMSE & $R^{2}$ & RMSE \\
\hline Nestos & 0.4616 & 1.1412 & 0.4395 & 1.1644 & 0.4609 & 1.1419 & 0.4678 & 1.1392 \\
\hline Queimados & 0.5706 & 0.5633 & 0.5281 & 0.5905 & 0.5664 & 0.5661 & 0.5720 & 0.5624 \\
\hline Rijnland & 0.2647 & 1.3010 & 0.2497 & 1.3141 & 0.2637 & 1.3019 & 0.2658 & 1.3003 \\
\hline Tamega & 0.3566 & 0.6610 & 0.3568 & 0.6609 & 0.3488 & 0.6650 & 0.3591 & 0.6597 \\
\hline Umbeluzi & 0.6706 & 0.5866 & 0.6827 & 0.5756 & 0.6440 & 0.6098 & 0.6842 & 0.5743 \\
\hline
\end{tabular}

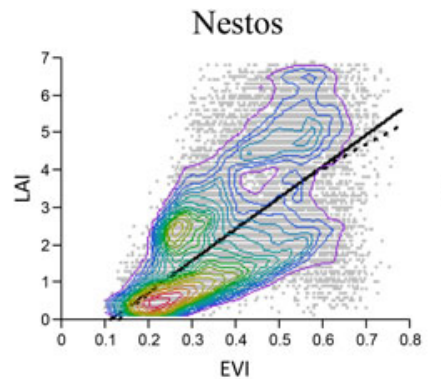

Tamega

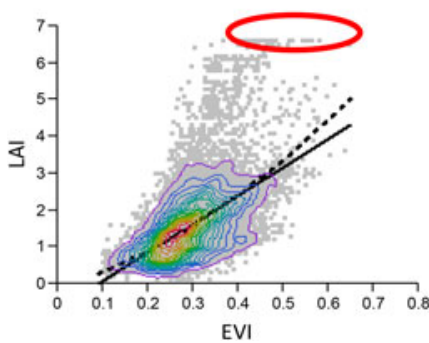

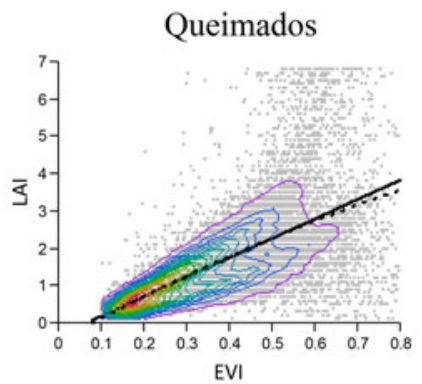

Umbeluzi

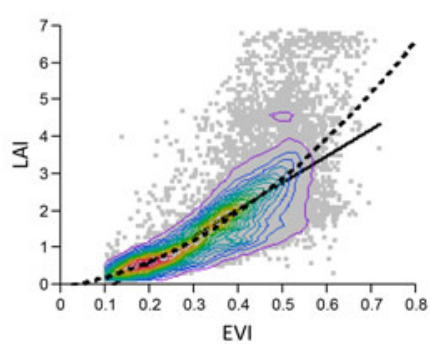

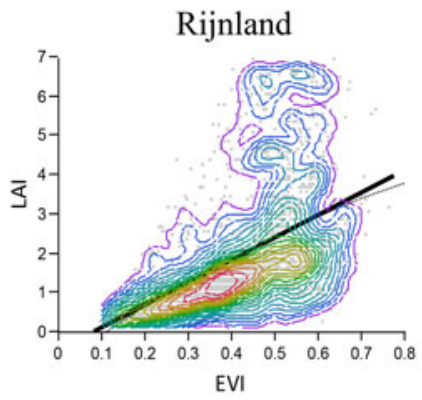

- Linear fit

- - - Polynomial fit

$\overline{1.2 .3 .4 .5 .6 .7 .8 .9}$

Quantile density colours

Figure 2. Linear and polynomial equations on the density scatter plots of LAI vs. EVI for all data per study area. An ellipse indicates possible saturation of EVI to high LAI values in the plot of the Tamega study area. 
Table 2. Linear regression equations between EVI and LAI per study area for all good data ( $N$ is the number of reliable pixels; $p$ is the $p$ value).

\begin{tabular}{lccccc}
\hline Site & $N$ & $R^{2}$ & Intercept & Slope & $p$ \\
\hline Nestos & 38900 & 0.4616 & -0.9416 & 8.4353 & $<.001$ \\
Queimados & 45398 & 0.5706 & -0.2975 & 5.1678 & $<.001$ \\
Rijnland & 2210 & 0.2647 & -0.4886 & 5.7599 & $<.001$ \\
Tamega & 22669 & 0.3566 & -0.6849 & 7.6922 & $<.001$ \\
Umbeluzi & 39508 & 0.6706 & -0.8298 & 7.1751 & $<.001$ \\
\hline
\end{tabular}

complexity of the polynomial equation and the marginal improvement, a linear equation was used for all subsequent analyses across all study areas.

The details of the linear regression equations that were applied to all good data pixels per study area are displayed in Table 2 . The $R^{2}$ showed a fluctuation from relatively high values in Umbeluzi and Queimados, to medium values in Nestos, whereas in Rijnland and Tamega only a small percentage of the variability was accounted for by the model. All of the results were statistically significant, as shown by the probability $(p)$ value. The slope of the equations was higher in Nestos, Tamega and Umbeluzi, demonstrating a higher sensitivity of LAI to EVI changes.

Analysis of the density plots showed that some points were drifting away from the regression line, having high LAI, while the EVI remained stable, being unable to describe the increasing LAI, as demonstrated in the example for the Queimados study area (red circle in Figure 2). These are signs of saturation of EVI at high biomass densities (high LAI).

\section{Relation across time}

In order to examine the EVI vs. LAI relation across time, the regression analysis was repeated for each Day Of the Year (DOY) along the hydrological year. While examining the $R^{2}$ per DOY significant changes were revealed during periods of unfavourable meteorological conditions (i.e. heavy cloud or snow cover), when the excluded data rate reached $100 \%$ in extreme cases (e.g. Rijnland from the end of October until February). Compared to the regression analysis for the whole year (Table 2), the $R^{2}$ remained at similar levels or were improved for all study areas during periods of high quality data (exclusion $<50-60 \%$ ).

For the dates that the exclusion of pixels was $>60 \%$, the majority of $R^{2}$ values were lower than the equivalent values when examined undivided for the whole year. In most cases (Nestos, Tamega, Umbeluzi) the difference of the values fluctuated between $20 \%$ and $30 \%$ and never dropped under $10 \%$. In most areas, $R^{2}$ values during November, February and March were low (Nestos, Rijnland and Tamega). However, there were also random dates during the rest of the year (e.g. Rijnland early summer) when low values were also present (Figure 3).

In order to compare the slope of the regression models across time, linear models were estimated with forcing the intercept equal to 0 (Figure 4). The analysis of the slope showed that sensitivity of LAI to EVI reached a maximum level between November and February for the study areas characterized by dry and warm climatic conditions, and between June and August for the rest of the study areas.

Examining the EVI vs. LAI scatter plots along seasons, there were notable changes in the data patterns during consecutive DOY in certain periods, which means that the EVI-LAI relation could dramatically change from one 16-day period to the next 


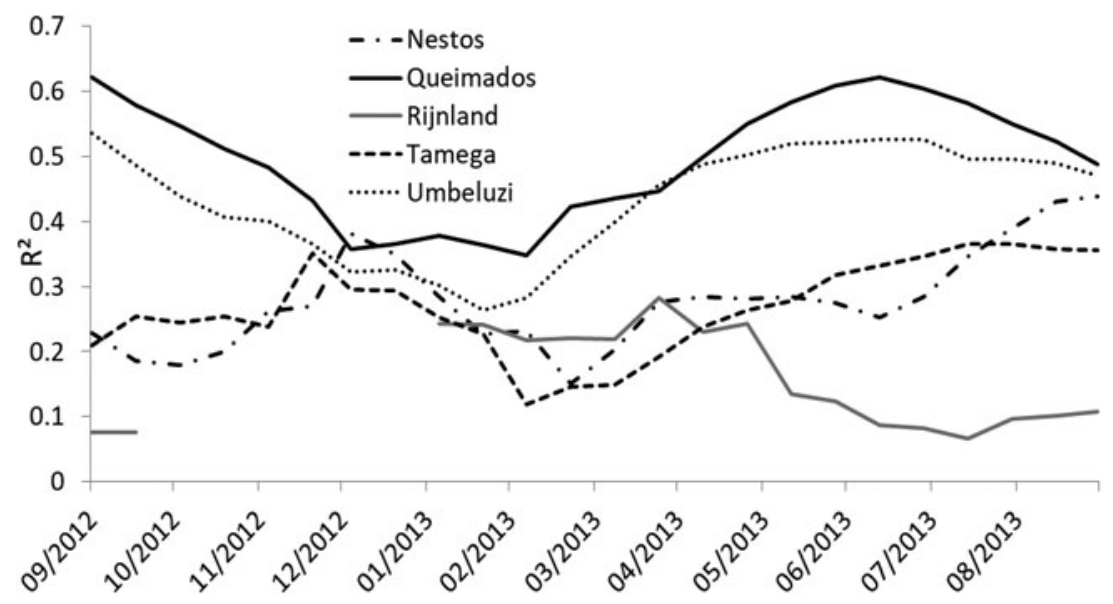

Figure 3. $R^{2}$ of linear model per DOY and study area.

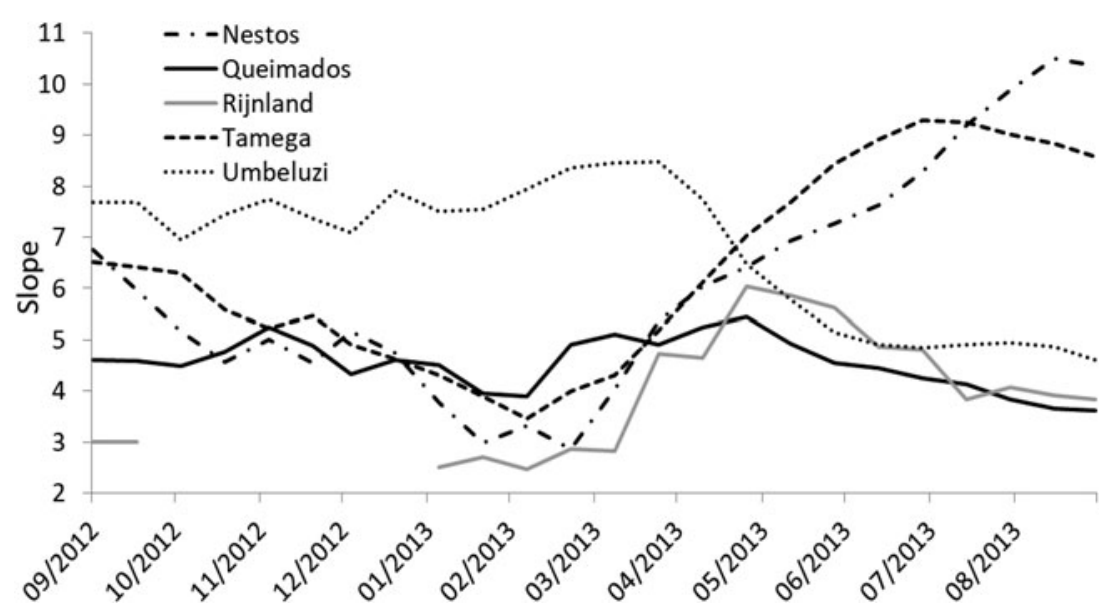

Figure 4. Slope of linear model when intercept $=0$ per DOY and study area.

(Figure 5). For instance, during December 2012 to January 2013 in Umbeluzi, the linear model increased in density forming two different lines on DOY 2013-001, which disappeared on the next DOY (Figure 5a). In another example, during March to May 2013 in Nestos (Figure 5b), several clusters of points were formed on DOY 2013-113 that were more prominent on the next DOY. During this period, the slope of the relation became steeper, revealing an increased sensitivity of EVI to LAI.

\section{Relation per vegetation type}

An overview of the $R^{2}$ estimated per vegetation type and study site can be found in Figure 6. Overall, a strong increase in $R^{2}$ values was noted compared to the results covering the whole year (Table 2). The $R^{2}$ was high and statistically significant (ranging from 0.41 to 0.83 in approximately $90 \%$ of the examined cases). There was no evident pattern characterizing certain vegetation types by higher or lower $R^{2}$ values when the study areas were examined as a total. However, there was a tendency in each study area - for different vegetation types - to have significantly lower $R^{2}$ values compared to the rest of the 
(a)
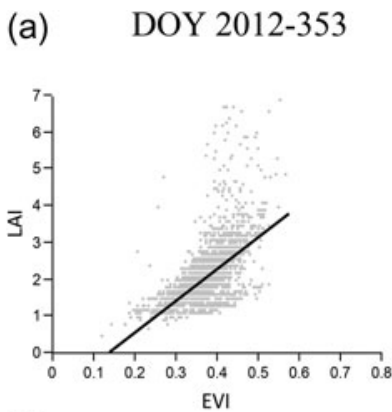

(b)

DOY 2013-097

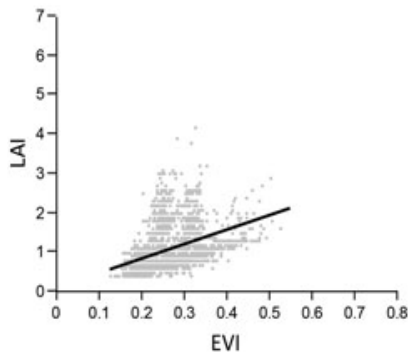

DOY 2013-001

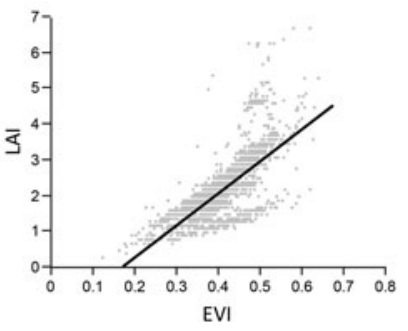

DOY 2013-113

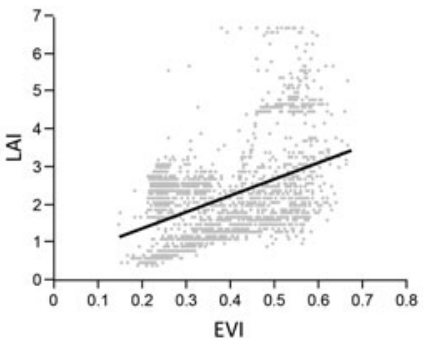

DOY 2013-017

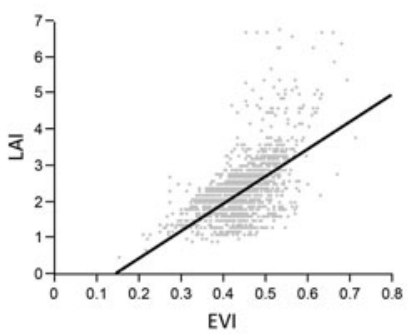

DOY 2013-129

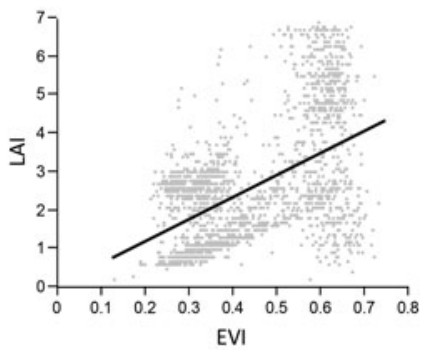

Figure 5. Scatter plots of LAI vs. EVI for three consecutive DOY for Umbeluzi (a) and Nestos (b) study sites.

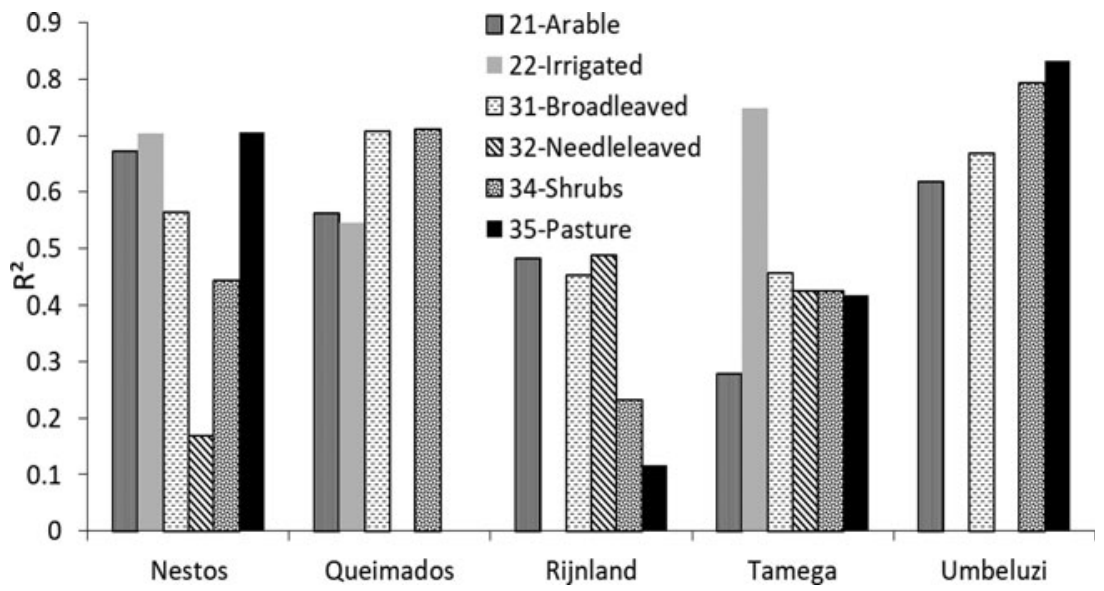

Figure 6. $R^{2}$ per vegetation type and study area.

existing vegetation types. For example, in areas with needle-leaved vegetation the EVI related to LAI with lower $R^{2}$ values for the study area of Nestos, but not for Rijnland and Tamega. The same situation was observed for shrublands of Nestos $\left(R^{2}=0.44\right)$ and Rijnland $\left(R^{2}=0.23\right)$, but in Umbeluzi the value of $R^{2}$ was close to 0.8 for this vegetation type. Irrigated crops overall showed stability in the EVI-LAI relation, with high $R^{2}$ values in all study areas where such data were available.

Examining the EVI vs. LAI scatter plots across vegetation types, there were study sites where the majority of the sampled pixels formed distinctive groups in certain areas of the plot showing similar values for EVI and LAI. For instance, in Nestos all vegetation types formed distinctive groups except the broadleaved forests (Figure 7a). Examining the 
(a)

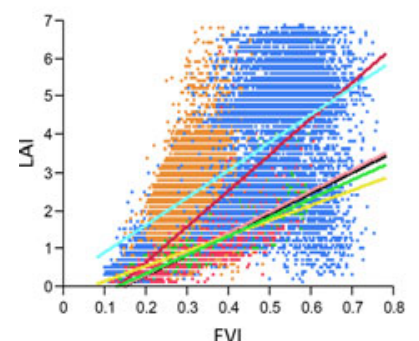

(b)

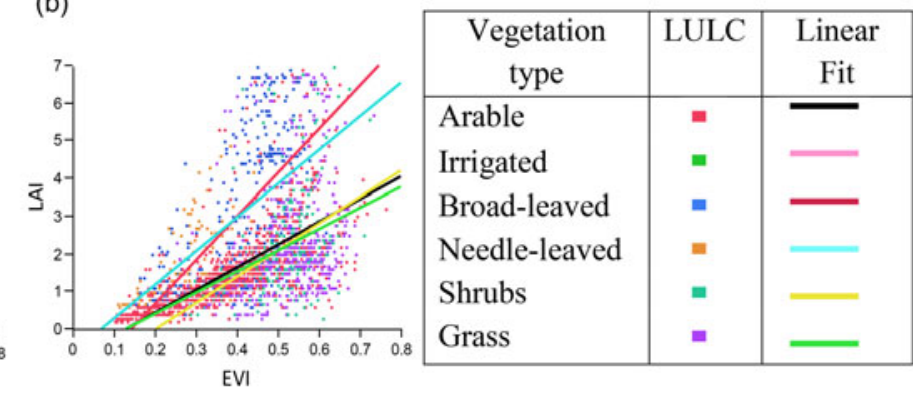

Figure 7. Examples of linear models per vegetation type on scatter plots for Nestos (a) and Rijnland (b).

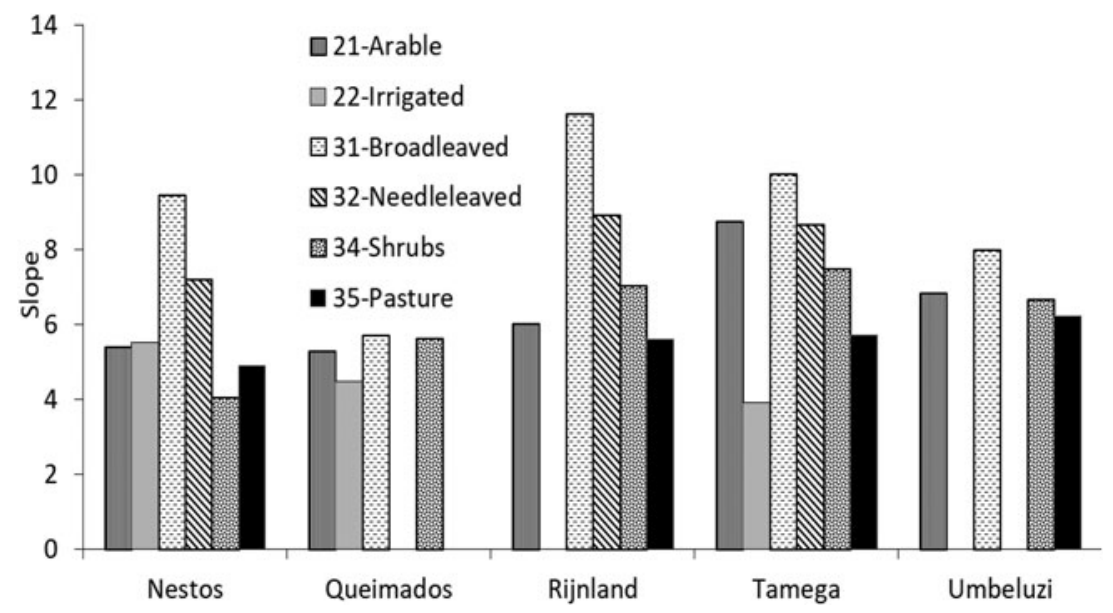

Figure 8. Slope of the linear model (intercept $=0$ ) per vegetation type and study area.

regression equation across these groups is the reason why the $R^{2}$ increased as compared to the $R^{2}$ of the whole study area. Nevertheless, there were study areas where the EVI vs. LAI scatter plots of all vegetation types were distributed in random patterns all over the plot, such as Rijnland (Figure $7 \mathrm{~b}$ ).

Linear models were estimated with forcing the intercept equal to 0 (Figure 8). The analysis of the slope showed that sensitivity of LAI to EVI is systematically high for broadleaved forests in all study sites, followed by needle-leaved forests for the sites where such vegetation was present.

\section{Discussion}

The relationship between MODIS EVI and LAI data was found to be adequately described by a linear equation for all study sites. Several studies have demonstrated the linearity of this relationship, for example, Potithep et al. (2013), while there are also studies supporting that a polynomial fit could better explain this relationship (Son et al. 2013). However, the results of these studies concern only certain vegetation types (e.g. specific crops or forest types), or specific study areas with certain climatic conditions. Through the present study, it was feasible to verify that this linear relation between LAI and EVI data of coarse resolution (MODIS products) is valid no matter what vegetation type or geographic area is examined, in the majority of the cases studied. Although a polynomial fit had slightly 
higher $R^{2}$ results, it was observed that the actual fit of a linear equation described better the distribution of the LAI-EVI data in the related plots. A solution to improve the results of the regression analysis as proposed by Wang, Adiku, et al. (2005) would be to examine more VIs simultaneously. However, this would dramatically affect the amount of data needed for all study areas.

Regression analysis between LAI and EVI showed a stronger relationship for the study sites with dry climatic conditions (Queimados - dry-tropical climate, and Umbeluzi warm-tropical climate), compared to the rest of the study sites (Nestos, Tamega, Rijnland). Adams (2009) reported that in dry and warm climates that cannot support a tree cover and the natural vegetation present is mainly open grasslands (such as the savannas in Umbeluzi) and shrublands (such as the 'cerrado' vegetation in Queimados), species richness tends to be lower, and therefore, intra-species vegetation homogeneity is higher. Both Queimados and Umbeluzi study areas are covered by shrubs and grasslands in the largest part of the site (more than $40 \%$ of the total study area in Queimados and more than $55 \%$ in Umbeluzi is covered by grass and shrub vegetation types). This fact, combined with the conclusions of Wang et al. (2004), Fang et al. (2012), Fensholt et al. (2004) and Privette et al. (2002) - reporting that vegetation homogeneity significantly increases the MODIS LAI accuracy, as well as that the MODIS LAI algorithm is more accurate for the biomes of grasses and shrubs (compared to those of forests) - could lead to the conclusion that the LAI-EVI relationship shows a stronger correlation in warm and dry climates. This is mainly connected to the vegetation types and their usual distribution among study areas with such climatic conditions (Adams 2009). This conclusion is also strengthened by the research of Tian et al. (2002), indicating that the dominant factor influencing the spatial distribution of LAI across the landscape is the variability within land cover types as opposed to differences between land cover types.

The analysis of QA layers showed that during cloudy conditions, the MODIS algorithm did not succeed in effectively detecting and flagging all the low quality data, which is evident from the sudden fluctuation of LAI values during consecutive 16-day periods of the time-series, something also noted by Wang, Tenhunen, et al. (2005). According to Ganguly et al. (2012), the LAI algorithm of MODIS cannot retrieve LAI values more precisely than its inputs, while they also warn that classification inaccuracies of land-cover data are a critical source of error in the LAI retrieval process. Tian et al. (2002) also added that the effect of misclassification is even larger when the spatial resolution of the data used is coarse, such as the MODIS data used in the present study. Data of finer spatial resolution that could be used as input data in the model (e.g. MODIS LAI product of $500 \mathrm{~m}$ pixel resolution, instead of $1000 \mathrm{~m}$ ) could significantly improve the overall model's accuracy (Johnson 2016).

The majority of the $R^{2}$ values of the regression analysis per DOY were found to be lower than the $R^{2}$ value estimated when all data of the time-series were considered. The analysis of the slope of the model showed that sensitivity of LAI vs. EVI reached a maximum level between November and February for the study areas with dry and warm tropical climatic conditions, and between June and August for the rest of the study areas. The highest sensitivity of LAI to EVI values was characterizing the broadleaved forests in all study areas, with needle-leaved forests following in areas where such a vegetation type was present. The sensitivity of EVI to LAI was lower in periods of high biomass and the sensitivity range was different across sites, probably also related to biomass quantity or type, since the EVI has improved sensitivity at high biomass regions (Wang, Tenhunen, et al. 2005). 
Vegetation type had the highest influence on the variation of the relationship between EVI and LAI, as $R^{2}$ values per vegetation type were found to be high in all cases examined during the regression analysis. However, this is also the parameter in cases in which biome misclassification of the data could impact the quality of the associated results. For example, in areas with needle-leaved vegetation, the EVI related to LAI with lower $R^{2}$ values for the study area of Nestos, but not for Rijnland and Tamega, something that could be caused by increased diversity of tree species in one area (increased heterogeneity), but not in the other. Indeed, vegetation heterogeneity has been reported to cause great underestimation of LAI and the magnitude of underestimation increases as vegetation heterogeneity increases (Fensholt et al. 2004). To account for this diversity, higher detail land cover maps should be used. The $R^{2}$ value of irrigated crops was the highest found among the examined cases, probably due to the increased homogeneity characterizing fields (study sites) with crops, compared to the natural vegetation types. Grasslands showed moderate to high values of $R^{2}$ in all study areas, except Rijnland. Since Rijnland is characterized by a relatively flat landscape and shallow groundwater level, it is possible that water inundation phenomena might be present in periods after heavy rainfall and in areas with poor drainage, which could affect the accuracy of LAI and EVI values. Agricultural areas and grasslands are more likely to be affected by such conditions. Moreover, the relatively small field size and the long and narrow shape that often characterizes the agricultural areas located in Rijnland, could also lead to erroneous identification of the vegetation type of such areas as mixed vegetation. In addition, grasslands are characterized by vertical and lateral homogeneity as well as a high ground cover, and because of this, the view angle influence is considered to be minor for this vegetation type (Myneni et al. 2002). Mowing effects could also be present; however, it was not possible to verify if such phenomena occurred.

Considering the reported uncertainty of the MODIS LAI product in several studies, it is well-known that the LAI of a single MODIS pixel is not retrieved accurately due to uncertainties in inputs and the product's algorithm, but the mean of multiple retrievals over a region with similar pixels is accurately retrieved, as proved by the research of Wang et al. (2004). In their study, testing with MODIS LAI data $(1 \mathrm{~km})$ in a forested area they showed that the mean variance is $48 \%$, which is higher than an overall uncertainty of $20 \%$ used by the operational MODIS LAI algorithm. However, they warned that forest biomes can be mixed with understory sprigs, shrubs, mosses and grasses within the highresolution LAI map pixel, causing high uncertainties in the specification of biome type which is input to the LAI algorithm. This could also be the case in the present study, since the sites with a strong presence of forested areas (and especially those with needleleaved forests), such as the Tamega, Rijnland and Nestos areas, showed relatively worse regression analysis results compared to the study areas of Queimados and Umbeluzi, where no needle-leaved forests are present. Fang et al. (2012) strengthen this conclusion with their study, finding that $40 \%$ of the MODIS LAI data used in their uncertainty assessment study of the product met the GCOS uncertainty requirement $\left(0.5 \mathrm{~m}^{2} / \mathrm{m}^{2}\right)$ throughout the year. This level of uncertainty was reported for the vegetation types of grasses, shrubs, crops and savannas, but not for the forested areas, where the uncertainty level was significantly higher. Tian et al. (2002) assessed the uncertainty of the MODIS LAI product via comparisons with ground and high-resolution satellite data, reporting in their results that the magnitude of LAI underestimation, dependent on the vegetation type, increased as spatial resolution decreased or vegetation heterogeneity increased (5\% underestimation of MODIS LAI values was found for their study site). In the present study, the coarse resolution of the MODIS products used $(1 \mathrm{~km})$ could have led to high 
vegetation heterogeneity within the same vegetation class, which could justify higher levels of uncertainty in the regression analysis results. Fensholt et al. (2004) evaluated the MODIS LAI product against in situ measurements at various homogeneous grassland sites in semi-arid Senegal (West Africa, 2001-2002), finding fairly accurate MODIS LAI $R^{2}$ values, while the overestimation of LAI values was between 0.03 and 0.4 units (2-15\%). The slightly higher homogeneity found for the vegetation classes of grasslands and shrublands at the study site of Umbeluzi, compared to the rest of the study sites, could justify the improved accuracy found in the relevant regression analysis results of this study area. This conclusion could also be enforced by Privette et al. (2002) who reported in their study assessing the LAI MODIS product of $1 \mathrm{~km}$ over semi-arid woodlands and savannas in Africa accurate results in both wet (dark soil) and dry (bright soil) seasons, as well as that the MODIS LAI product performed well for their study areas. Fang et al. (2012) found that the MODIS LAI product underestimates the upper range of in situ LAI measurements in forested areas, with their results indicating temporal gaps and unrealistically strong variability during the growing season. The overall LAI accuracy in their study was estimated close to $\pm 1.0 \mathrm{~m}^{2} / \mathrm{m}^{2}$. Additionally, they reported that especially for the shrubs and savanna biomes, the LAI accuracy was improved ( \pm 0.5 unit) due to the small average LAI values characterizing these two biomes, which - compared to other study areas could be connected with the higher regression analysis results found in Umbeluzi and Queimados, in which sites there is a strong presence of grasslands and shrublands. All the above-mentioned studies and their associated results indicate that the MODIS LAI product is often characterized by higher uncertainty than the one theoretically expected by the product developers, but still can be accurate over most vegetation types, except forested areas.

Several limitations were identified during the progress of this study. The compositing method used for the MODIS products is likely to have contributed to the observed differences during consecutive DOYs. First of all, the LAI product uses an 8-day compositing period as compared to the 16-day compositing period of EVI. Another difference of the two products is the method of selecting the data within the compositing period, which is based on the highest fPAR value for the LAI product and on the proximity of the viewing angle to nadir for the EVI product. Consequently, in agricultural vegetation types, a high LAI value of a crop during the last days before harvesting might be paired with a low value of EVI for the same DOY, if the closer to nadir EVI value coincides with the days just after harvesting. The same phenomenon could also occur at dates when rapid greenup of leaves occurs in a period of 10-12 days, as warned by Ahl et al. (2006). Indeed, a higher observation frequency should be used for all vegetation types during spring in Greece, as noted by Alexandridis et al. (2008). Additionally, the standard VI and LAI products of MODIS may contain significant directional noise as supported by Huete et al. (2002). Tian et al. (2000) found that a 1-km MODIS LAI pixel could be underestimated by $5 \%$ compared to field measurements if resolution of the data is not taken into consideration.

Another source of uncertainty lies in the potential saturation of the EVI signal at high biomass densities, thus rendering the EVI incapable of describing LAI correctly. This has been documented for other VIs too, such as the Simple Ratio (SR), the NDVI and the Soil-Adjusted Vegetation Index (SAVI) (Turner et al. 1999). Thus, saturation could explain the low $R^{2}$ in forests, where except for the dense canopy, the presence of understory vegetation could aggravate the effect causing insensitivity of reflectance to model vegetation (Fensholt et al. 2004). In addition, pixels of low resolution images, such as in the MODIS products, are likely to contain an amount of radiative contribution from the 
background (Myneni et al. 2002), thus saturation is not likely to affect sparse biomes such as shrublands and grasslands (Fensholt et al. 2004).

\section{Conclusions}

The results of this study showed that a linear model can describe the relationship between MODIS EVI and LAI across all examined vegetation types and dates. Although medium accuracy models have been found in some test sites, these were improved when variability of time and vegetation type was considered.

Vegetation type has the highest influence on the relationship between LAI and EVI, for all study sites examined. The sensitivity of EVI to LAI was highest in periods of high biomass production. In some case studies, a high percentage of variability of LAI was explained by the linear regression equation with EVI, thus the equation could be used to predict LAI with a high degree of confidence. Regression analysis between LAI and EVI showed a stronger relationship for the study sites characterized by dry and warm tropical climatic conditions.

The limited number of pixels available for some vegetation types at specific DOYs, the diversity of vegetation species within the same vegetation types in the study areas, as well as saturated EVI values, were the most probable factors affecting the regression analysis results.

\section{Disclosure statement}

No potential conflict of interest was reported by the authors.

\section{Funding}

This work was supported by the Research Committee of the Aristotle University of Thessaloniki (Greece), grant number 90773 "Improvement of the estimation of Leaf Area Index (LAI) at basin scale using satellite images".

\section{ORCID}

Thomas K. Alexandridis (iD http://orcid.org/0000-0003-1893-6301

Georgios Ovakoglou (iD http://orcid.org/0000-0001-7195-6112

Jan G. P. W. Clevers (iD http://orcid.org/0000-0002-0046-082X

\section{References}

Adams J. 2009. Vegetation-climate interaction: how plants make the global environment. New York: Springer Science \& Business Media.

Ahl DE, Gower S, Burrows S, Shabanov N, Myneni R, Knyazikhin Y. 2006. Monitoring spring canopy phenology of a deciduous broadleaf forest using MODIS. Remote Sens Environ. 104(1):88-95.

Alexandridis T, Gitas I, Silleos N. 2008. An estimation of the optimum temporal resolution for monitoring vegetation condition on a nationwide scale using MODIS/Terra data. Int J Remote Sens. 29(12): 3589-3607.

Alexandridis T, Stavridou D, Strati S, Monachou S, Silleos N. 2013. LAI measurement with hemispherical photographs at variable conditions for assessment of remotely sensed estimations. ESA living planet symposium. Vol. 252. Edinburgh, UK: ESA.

Butson C, Fernandes R. 2004. A consistency analysis of surface reflectance and leaf area index retrieval from overlapping clear-sky Landsat ETM + imagery. Remote Sens Environ. 89(3):369-380. 
Chen J, Sun L. 2010. Using MODIS EVI to detect vegetation damage caused by the 2008 ice and snow storms in south China. J Geophys Res: Biogeosci. 115(G3). https://doi.org/10.1029/2009JG001246

Clevers JGPW. 1989. Application of a weighted infrared-red vegetation index for estimating leaf area index by correcting for soil moisture. Remote Sens Environ. 29(1):25-37.

Fang H, Wei S, Jiang C, Scipal K. 2012. Theoretical uncertainty analysis of global MODIS, CYCLOPES, and GLOBCARBON LAI products using a triple collocation method. Remote Sens Environ. 124: $610-621$.

Fang H, Wei S, Liang S. 2012. Validation of MODIS and CYCLOPES LAI products using global field measurement data. Remote Sens Environ. 119:43-54.

Fensholt R, Sandholt I, Rasmussen MS. 2004. Evaluation of MODIS LAI, fAPAR and the relation between fAPAR and NDVI in a semi-arid environment using in situ measurements. Remote Sens Environ. 91(3-4):490-507.

Ganguly S, Nemani RR, Zhang G, Hashimoto H, Milesi C, Michaelis A, Wang W, Votava P, Samanta A, Melton F, et al. 2012. Generating global leaf area index from Landsat: algorithm formulation and demonstration. Remote Sens Environ. 122:185-202.

Goel N. 1989. Inversion of canopy reflectance models for estimation of biophysical parameters from reflectance data. In: Asrar G, editor. Theory and applications of optical remote sensing. Wiley Series in Remote Sensing and Image Processing. New York: Wiley; p. 205-250.

Huete A, Didan K, Miura T, Rodriguez EP, Gao X, Ferreira LG. 2002. Overview of the radiometric and biophysical performance of the MODIS vegetation indices. Remote Sens Environ. 83(1-2):195-213.

Huete A, Justice C, Van Leeuwen W. 1999. MODIS vegetation index (MOD 13): Algorithm Theoretical Basis Document (ATBD) v.3.0. http://gis-lab.info/docs/atbd_mod13.pdf.

Huete AR, Liu HQ, Batchily K, Van Leeuwen WJDA. 1997. A comparison of vegetation indices over a global set of TM images for EOS-MODIS. Remote Sens Environ. 59(3):440-451.

Jassas H, Kanoua W, Merkel B. 2015. Actual evapotranspiration in the Al-Khazir Gomal Basin (Northern Iraq) using the surface energy balance algorithm for land (SEBAL) and water balance. Geosciences. 5(2):141-159.

Johnson DM. 2016. A comprehensive assessment of the correlations between field crop yields and commonly used MODIS products. Int J Appl Earth Observ Geoinform. 52:65-81.

Kimes DS, Knyazikhin Y, Privette JL, Abuelgasim AA, Gao F. 2000. Inversion methods for physicallybased models. Remote Sens Rev. 18(2-4):381-439.

Knyazikhin Y, Glassy J, Privette JL, Tian Y, Lotsch A, Zhang Y, Wang Y, Morisette JT, Votava P, Myneni RB. 1999. MODIS leaf area index (LAI) and fraction of photosynthetically active radiation absorbed by vegetation (FPAR) product (MOD15) algorithm theoretical basis document. Theoretical Basis Document, NASA Goddard Space Flight Center, Greenbelt, MD, 20771.

Meroni M, Colombo R, Panigada C. 2004. Inversion of a radiative transfer model with hyperspectral observations for LAI mapping in poplar plantations. Remote Sens Environ. 92(2):195-206.

Myneni R. 2012. MODIS LAI/FPAR Product User's Guide. USGS LP DAAC. https://lpdaac.usgs.gov/sites/ default/files/public/modis/docs/MODIS-LAI-FPAR-User-Guide.pdf.

Myneni RB, Hoffman S, Knyazikhin Y, Privette JL, Glassy J, Tian Y, Wang Y, Song X, Zhang Y, Smith GR, et al. 2002. Global products of vegetation leaf area and fraction absorbed PAR from year one of MODIS data. Remote Sens Environ. 83(1-2):214-231.

Nyokabi MW, Laneve G. 2004. Vegetation index calibration for dry arid ecosystems of eastern Africa. Paper presented at the Geoscience and Remote Sensing Symposium, 2004. IGARSS'04. Proceedings. 2004 IEEE International.

Potithep S, Nagai S, Nasahara KN, Muraoka H, Suzuki R. 2013. Two separate periods of the LAI-VIs relationships using in situ measurements in a deciduous broadleaf forest. Agric For Meteorol. 169: $148-155$.

Privette JL, Myneni RB, Knyazikhin Y, Mukelabai M, Roberts G, Tian Y, Wang Y, Leblanc SG. 2002. Early spatial and temporal validation of MODIS LAI product in the Southern Africa Kalahari. Remote Sens Environ. 83(1-2):232-243.

Shen L, Li Z, Guo X. 2014. Remote sensing of leaf area index (LAI) and a spatiotemporally parameterized model for mixed grasslands. Int J Appl Sci Technol. 4(1):46-61.

Silleos N, Strati S, Cherif I, Topaloglou C, Alexandridis TK, Iordanidis C, Stavridou D, Monachou S, Kalogeropoulos C, Bilas G. 2014. Weekly time series of LAI maps at river basin scale using MODIS satellite data. In 1st international GEOMAPPLICA conference.

Son NT, Chen CF, Chen CR, Chang LY, Duc HN, Nguyen LD. 2013. Prediction of rice crop yield using MODIS EVI - LAI data in the Mekong Delta, Vietnam. Int J Remote Sens. 34(20):7275-7292. 
Soudani K, François C, Le Maire G, Le Dantec V, Dufrêne E. 2006. Comparative analysis of IKONOS, SPOT, and ETM + data for leaf area index estimation in temperate coniferous and deciduous forest stands. Remote Sens Environ. 102(1-2):161-175.

Teixeira AH. 2010. Determining regional actual evapotranspiration of irrigated crops and natural vegetation in the São Francisco River Basin (Brazil) using remote sensing and Penman-Monteith Equation. Remote Sens. 2(5):1287-1319.

Tian Y, Woodcock CE, Wang Y, Privette JL, Shabanov NV, Zhou L, Zhang Y, Buermann W, Dong J, Veikkanen B. 2002. Multiscale analysis and validation of the MODIS LAI product: I. Uncertainty assessment. Remote Sens Environ. 83(3):414-430.

Tian Y, Zhang Y, Knyazikhin Y, Myneni RB, Glassy JM, Dedieu G, Running SW. 2000. Prototyping of MODIS LAI and FPAR algorithm with LASUR and LANDSAT data. IEEE Trans Geosci Remote Sens. 38(5):2387-2401.

Turner DP, Cohen WB, Kennedy RE, Fassnacht KS, Briggs JM. 1999. Relationships between leaf area index and Landsat TM spectral vegetation indices across three temperate zone sites. Remote Sens Environ. 70(1):52-68.

Wang Q, Adiku S, Tenhunen J, Granier A. 2005. On the relationship of NDVI with leaf area index in a deciduous forest site. Remote Sens Environ. 94(2):244-255.

Wang Q, Tenhunen J, Dinh NQ, Reichstein M, Otieno D, Granier A, Pilegarrd K. 2005. Evaluation of seasonal variation of MODIS derived leaf area index at two European deciduous broadleaf forest sites. Remote Sens Environ. 96(3-4):475-484.

Wang Y, Woodcock CE, Buermann W, Stenberg P, Voipio P, Smolander H, Häme T, Tian Y, Hu J, Knyazikhin Y, Myneni RB. 2004. Evaluation of the MODIS LAI algorithm at a coniferous forest site in Finland. Remote Sens Environ. 91(1):114-127. 